\title{
The implications of a tracheal bronchus on one-lung ventilation and fibreoptic bronchoscopy in a patient undergoing thoracic surgery: a case report \\ Implications d'une bronche trachéale sur la ventilation à un seul poumon et la bronchoscopie par fibre optique chez un patient subissant une chirurgie thoracique: une étude de cas
}

\author{
Young-Jin Moon, MD · Sung-Hoon Kim, MD • \\ Sang Wook Park, MD $\cdot$ Yu Mi Lee, MD \\ Received: 8 August 2014/Accepted: 8 December 2014/Published online: 16 December 2014 \\ (C) Canadian Anesthesiologists' Society 2014
}

\begin{abstract}
Purpose Due to its anatomical complexity, a tracheal bronchus has important clinical implications for one-lung ventilation $(O L V)$. We present a case of successful OLV in a patient with a high a type I (i.e., high take-off) tracheal bronchus. This anomaly presented unusual fibreoptic bronchoscopic (FOB) views that were difficult to discern from the normal carinal bifurcation.

Clinical features A 35-yr-old male presented for posterior basal segmentectomy of the left lower lobe under video-assisted thoracoscopy. The preoperative chest radiography was reported as normal, but a computed tomography scan of the chest revealed a right upper lobe tracheal bronchus. The inlet of the tracheal bronchus was located high above the carina, and the distal trachea had significant narrowing. Because the main trachea was divided into a tracheal bronchus and a distal trachea with similar diameters and with an acute angle of divergence, FOB views of the tracheal bronchus take-off appeared similar to the normal carinal bifurcation. Moreover, the actual carina had an atypical appearance
\end{abstract}

Author contributions Young-Jin Moon and Sung-Hoon Kim were responsible for the conception of the case report and writing the manuscript. Sang-Wook Park and $\mathrm{Yu}$-Mi Lee were involved in anesthetic management of the patient and also gave important suggestions during manuscript preparation.

Y.-J. Moon, MD · S.-H. Kim, MD (ه) · S. W. Park, MD

Y. M. Lee, MD

Department of Anesthesiology and Pain Medicine, Asan Medical

Center, University of Ulsan College of Medicine, 388-1, Pungnap 2-

dong, Songpa-gu, Seoul, Korea

e-mail: shkimans@amc.seoul.kr with the main bronchi shifted laterally and a blunted carinal ridge. As a result of this atypical tracheobronchial anatomy, we used an Arndt endobronchial blocker system instead of a double-lumen tube (DLT) for right-sided OLV. One-lung ventilation was satisfactory throughout the uncomplicated operation.

Conclusion Careful preoperative assessment of tracheobronchial anatomy is imperative in order to choose an appropriate method of OLV and prevent potential complications. In a type I tracheal bronchus with a narrowed distal trachea, a bronchial blocker may have advantages over the conventional DLT in achieving OLV.

\begin{abstract}
Résumé
Objectif Compte tenu de sa complexité anatomique, une bronche trachéale a d'importantes implications cliniques sur la ventilation à un seul poumon $(O L V)$. Nous présentons un cas d'OLV réussie chez un patient ayant un type I haut, c'est-à-dire un embranchement haut-situé de la bronche trachéale. En bronchoscopie à fibre optique (FOB), cette anomalie présentait des images peu communes difficiles à discerner d'une carène de bifurcation normale.

Caractéristiques cliniques Un homme âgé de 35 ans a été hospitalisé pour segmentectomie basale postérieure du lobe inférieur gauche par thoracoscopie assistée par vidéo. La radiographie préopératoire du thorax a été décrite comme normale, mais une tomodensitométrie du thorax a révélé une bronche trachéale du lobe supérieur droit. Le départ de la bronche trachéale était situé haut par rapport à la carène et la trachée distale était significativement rétrécie. Dans la mesure où la trachée proprement dite se divisait en bronche trachéale et en trachée distale, aux
\end{abstract}


diamètres semblables et avec une bifurcation formant un angle aigu, les vues en FOB du départ de la bronche trachéale ressemblaient à celles d'une carène normale. De plus, la véritable carène avait un aspect atypique avec des bronches souches déplacées latéralement et une crête de carène émoussée. Du fait de cette anatomie trachéobronchique atypique, nous avons utilisé un système de blocage endobronchique d'Arndt à la place d'un tube à double lumière (DLT) pour une OLV du côté droit. La ventilation unilatérale a été satisfaisante tout au long de l'intervention qui s'est déroulée sans complication. Conclusion Une évaluation préopératoire soigneuse de l'anatomie trachéobronchique est impérative pour choisir une méthode appropriée d'OLV et prévenir les complications potentielles. Dans le cas d'une bronche trachéale de type I avec trachée distale rétrécie, un bloqueur bronchique peut avoir des avantages par rapport à un DLT conventionnel pour la réalisation d'une OLV.

A tracheal bronchus, defined as an aberrant bronchus originating from the main trachea, has a reported incidence of $0.1-3 \%{ }^{1}$ Although many patients with a tracheal bronchus can have a history of recurrent respiratory infection during their childhood, most patients remain asymptomatic until the tracheal bronchus is found incidentally during fibreoptic bronchoscopy (FOB). ${ }^{2}$ There is usually little clinical significance for non-thoracic surgery in asymptomatic patients with a tracheal bronchus; ${ }^{3}$ however, when airway management for one-lung ventilation $(\mathrm{OLV})$ is required, the procedure may be complicated because of an atypical origin of the tracheal bronchus. We present a case of successful OLV using a single-lumen endotracheal tube (ETT) with a bronchial blocker in a patient with a tracheal bronchus that presented atypical FOB views of the tracheal bronchus inlet, distal trachea, and tracheal carina.

\section{Case report}

A previously healthy 35-yr-old (height: $165 \mathrm{~cm}$, weight: $68 \mathrm{~kg}$ ) male presenting with hemoptysis was diagnosed with intralobar-type pulmonary sequestration and scheduled for posterior basal segmentectomy of the left lower lobe under video-assisted thoracoscopy. Preoperative evaluations, including chest radiography, electrocardiography, and laboratory tests were unremarkable. Preoperative computed tomography revealed aberrant take-off of the right upper lobe bronchus arising from the trachea (i.e., tracheal bronchus; Figure A). The tracheal bronchus (10.7 $\mathrm{mm}$ in diameter) originated $4.6 \mathrm{~cm}$ above the carina. The diameter of the trachea $(11.9 \mathrm{~mm})$ measured at the level of the clavicle was smaller than the norm $(13-25 \mathrm{~mm}){ }^{4}$ and distal to the tracheal bronchus, the diameter of the trachea was $9.8 \mathrm{~mm}$.

After applying standard monitoring, ${ }^{5}$ general anesthesia was induced with intravenous propofol. Neuromuscular blockade was achieved with rocuronium, and anesthesia was maintained with a continuous infusion of remifentanil and sevoflurane $1-3 \mathrm{vol} \%$ in $50 \%$ air/oxygen. The patient's trachea was intubated with a Mallinckrodt ${ }^{\mathrm{TM}}$ single-lumen ETT (Covidien Inc., Mansfield, MA, USA) with an 8.0-mm internal diameter. Fibreoptic bronchoscopy revealed that the take-off of the tracheal bronchus mimicked the appearance of the normal carinal bifurcation (Figure B). The trachea was divided into the tracheal bronchus and the main trachea, forming a sharp ridge at the junction where they diverged. As the FOB advanced further into the main trachea, the patient's actual tracheal carina was visualized (Figure C). Compared with a normal carinal appearance, our patient's carina showed an atypical appearance with a laterally shifted main bronchi forming an obtuse angle of divergence with a blunted carinal ridge.

Considering the high location of the tracheal bronchus and the narrow distal trachea, we opted to use a 9 Fr Arndt endobronchial blocker (Cook Critical Care, Bloomington, IN, USA) to allow for lung isolation and OLV. The FOB was threaded through the wire loop of the bronchial blocker and advanced into the left main bronchus. The FOB was then withdrawn, leaving the bronchial blocker in the left main bronchus. The balloon of the bronchial blocker was inflated under FOB visualization, and the proper position of the bronchial blocker was confirmed by FOB visualization before and after placing the patient in a lateral decubitus position. One-lung ventilation was satisfactory throughout the surgery with the $\mathrm{SaO}_{2}$ maintained at $100 \%$ with peak inspiratory pressures of $25-27 \mathrm{~cm} \mathrm{H}_{2} \mathrm{O}$. The surgery proceeded uneventfully with good lung deflation and operating conditions. The patient was discharged from hospital on postoperative day 4 without any complications.

\section{Discussion}

Achieving OLV in patients with a tracheal bronchus anomaly can be a complicated problem because of the associated anatomical complexity. For example, in our case, the tracheal bronchus inlet appeared to mimic the normal carinal bifurcation. If not recognized, this structural similarity could delay recognition of the tracheal bronchus and lead to malpositioning the ETT and the OLV device. For instance, if the bronchial blocker balloon were placed just distal to the tracheal bronchus take-off and inflated, it would have led to obstruction of the left lung as well as the 


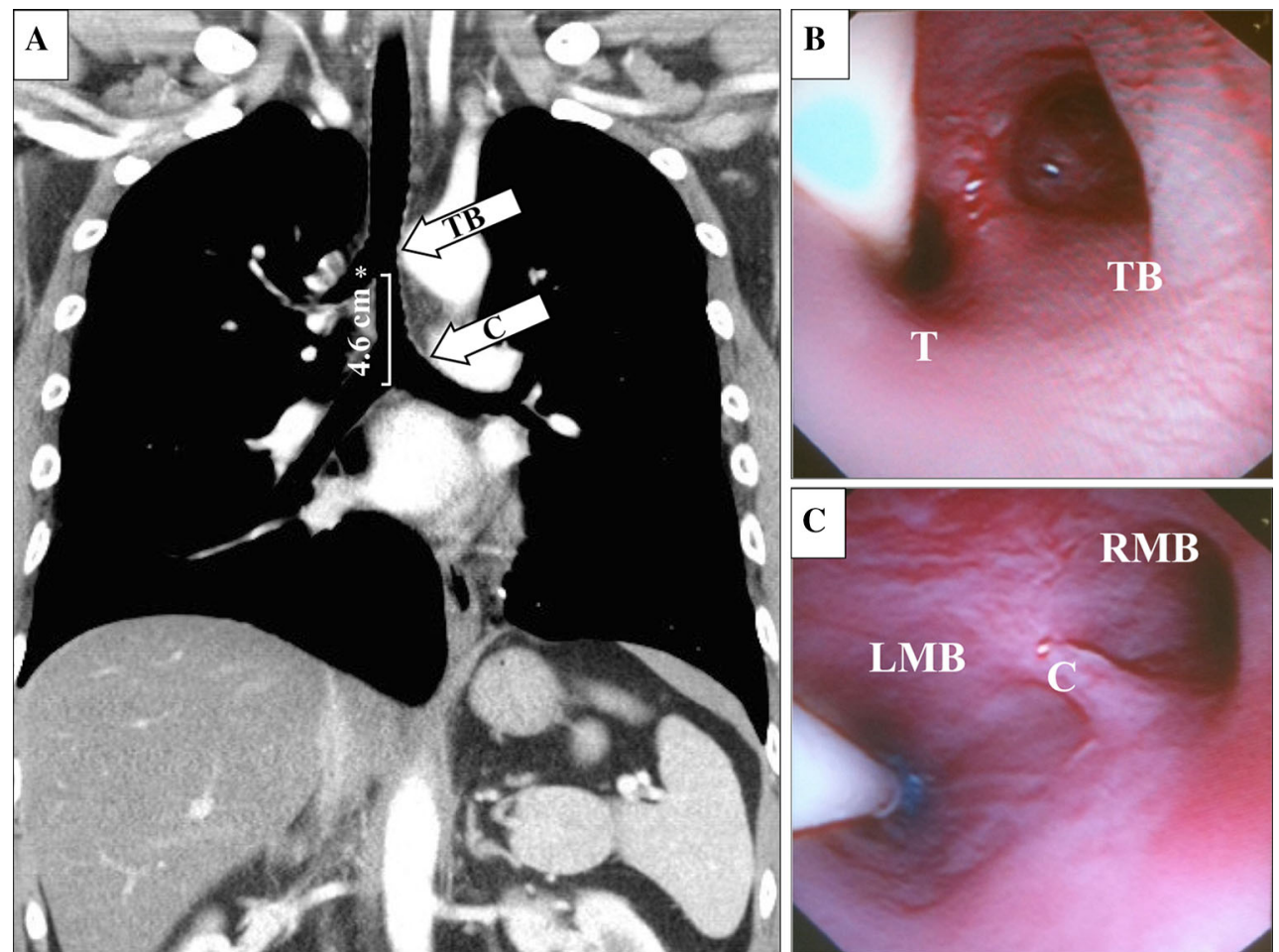

Figure A) A preoperative computed tomography scan of the patient's chest revealed a tracheal bronchus (TB; asterisk) of the right upper lobe originating from the middle of the trachea (T) $4.6 \mathrm{~cm}$ above the carina. The labelled upper and lower white arrows correspond to the fibreoptic bronchoscopic (FOB) views at the level of the tracheal bronchus bifurcation and the carina $(\mathrm{C})$, respectively.

right middle and lower lobes with resulting atelectasis, hypoxemia, and high airway pressures.,

There are various classifications of tracheal bronchus, but a simple classification was described by Conacher et $a l .^{3}$ According to this classification, our case was a type I tracheal bronchus, which is defined as a tracheal bronchus originating $\geq 2 \mathrm{~cm}$ above the carina with distal tracheal narrowing. Compared with other types of tracheal bronchus, it is particularly difficult to achieve OLV in patients with a type I tracheal bronchus ${ }^{3,6}$ as the bifurcation site is easily confused with the normal tracheobronchial carinal anatomy. As a result, if the tracheal bronchus is not diagnosed preoperatively, the anesthesiologist may not necessarily suspect a tracheal bronchus even after FOB. ${ }^{3,6}$ Moreover, distal narrowing of the trachea can also limit the methods of OLV. As the main body of a double-lumen endotracheal tube (DLT) has an outer diameter of 12$14 \mathrm{~mm}$, airway trauma could occur with its placement in a narrowed distal trachea. ${ }^{7}$

Although a DLT has previously been used successfully for OLV in patients with a tracheal bronchus, ${ }^{8,9}$ in those cases, the distance between the tracheal bronchus and carina was close enough not to interfere with the tracheal lumen of the DLT, and both main bronchi had no
B) The FOB view of the tracheal bronchus bifurcation that appears to mimic the appearance of a normal carinal bifurcation. C) The FOB view showing the carina, right mainstem bronchus (RMB), and the properly positioned endobronchial blocker in the left mainstem bronchus (LMB)

anatomical distortion. A previous report showed that a left-sided DLT could be used successfully to achieve OLV in most tracheal bronchi, because most originate from within $2 \mathrm{~cm}$ above the carina. ${ }^{10}$ Nevertheless, there are reports showing that use of a DLT failed to achieve OLV because of a left-shifted carina and an apically retracted left main bronchus, even though the tracheal bronchus was within $2 \mathrm{~cm}$ of the carina. ${ }^{11,12}$ In our case, the margin of safety to position the tracheal lumen of the DLT could not be assured because of the higher than usual take-off of the tracheal bronchus. ${ }^{7}$

Use of a bronchial blocker allowed OLV regardless of the anatomical distortion and bronchial diameter. ${ }^{13}$ Use of a number of different bronchial blocker systems have been reported in patients with a tracheal bronchus requiring OLV. ${ }^{6,11}$ In the present case, we thought that the Arndt system would be useful because the bronchial blocker had to pass through a bifurcation site twice in order to reach the left main bronchus; thus, it might have been more difficult to place a bronchial blocker without any intrinsic wire guidance. Other types of bronchial blockers, such as the Cohen Flexitip (Cook, Bloomington, IN, USA) and the Fuji Uniblocker (Fuji Systems, Tokyo, Japan) can be used to achieve OLV, but the procedure might be technically 
difficult and more time-consuming. The EZ-Blocker ${ }^{\circledR}$ (IQ Medical Ventures BV, Rotterdam, Netherlands) would not have been appropriate for the current case, as the Y-shaped distal end of the blocker would have caused it to be anchored onto the tracheal bronchus bifurcation before it reached the actual carina.

In summary, we successfully achieved OLV in a patient with a type I tracheal bronchus using an Arndt wire-guided endobronchial blocker. Careful preoperative assessment of tracheobronchial anatomy is imperative in order to choose an appropriate method of OLV and prevent potential complications. In a tracheal bronchus with a high take-off of more than $2 \mathrm{~cm}$ above the carina, a bronchial blocker may have advantages over a conventional DLT.

Acknowledgement The authors thank Dr. Ji-Hyun Park for her help in preparing this manuscript.

Conflicts of interest None declared.

\section{References}

1. Barat M, Konrad HR. Tracheal bronchus. Am J Otolaryngol 1987; 8: 118-22.

2. McLaughlin FJ, Strieder DJ, Harris GB, Vawter GP, Eraklis AJ. Tracheal bronchus: association with respiratory morbidity in childhood. J Pediatr 1985; 106: 751-5.
3. Conacher ID. Implications of a tracheal bronchus for adult anaesthetic practice. Br J Anaesth 2000; 85: 317-20.

4. Breatnach E, Abbott GC, Fraser RG. Dimensions of the normal human trachea. AJR Am J Roentgenol 1984; 142: 903-6.

5. Merchant RN, Chartrand D, Dain S, et al. Guidelines to the practice of anesthesia - revised edition 2014. Can J Anesth 2014; 61: 46-59.

6. Iwamoto $T$, Takasugi $Y$, Hiramatsu $K$, et al. Three-dimensional CT image analysis of a tracheal bronchus in a patient undergoing cardiac surgery with one-lung ventilation. J Anesth 2009; 23: 260-5.

7. Brodsky JB, Macario A, Mark JB. Tracheal diameter predicts double-lumen tube size: a method for selecting left double-lumen tubes. Anesth Analg 1996; 82: 861-4.

8. Lee HL, Ho AC, Cheng RK, Shyr MH. Successful one-lung ventilation in a patient with aberrant tracheal bronchus. Anesth Analg 2002; 95: 492-3.

9. Lee DK, Kim YM, Kim HZ, Lim SH. Right upper lobe tracheal bronchus: anesthetic challenge in one-lung ventilated patients - a report of three cases. Korean J Anesthesiol 2013; 64: 448-50.

10. Ho AM, Karmakar MK, Lam WW, et al. Does the presence of a tracheal bronchus affect the margin of safety of double-lumen tube placement? Anesth Analg 2004; 99: 293-5.

11. Wiser SH, Hartigan PM. Challenging lung isolation secondary to aberrant tracheobronchial anatomy. Anesth Analg 2011; 112: 688-92.

12. Yoshimura T, Ueda K, Kakinuma A, Nakata $Y$. Difficulty in placement of a left-sided double-lumen tube due to aberrant tracheobronchial anatomy. J Clin Anesth 2013; 25: 413-6.

13. Campos JH. Which device should be considered the best for lung isolation: double-lumen endotracheal tube versus bronchial blockers. Curr Opin Anaesthesiol 2007; 20: 27-31. 